\title{
Diversity and evolution of Bdellovibrio-and-like organisms (BALOs), reclassification of Bacteriovorax starrii as Peredibacter starrii gen. nov., comb. nov., and description of the Bacteriovorax-Peredibacter clade as Bacteriovoracaceae fam. nov.
}

\author{
Correspondence \\ Edouard Jurkevitch \\ jurkevi@agri.huji.ac.il \\ Yaacov Davidov \\ davidov@agri.huji.ac.il
}

\section{Yaacov Davidov and Edouard Jurkevitch}

\begin{abstract}
Department of Plant Pathology and Microbiology, Faculty of Agricultural, Food and Environmental Quality Sciences, The Hebrew University of Jerusalem, PO Box 12, Rehovot 76100, Israel
\end{abstract}

\begin{abstract}
A phylogenetic analysis of Bdellovibrio-and-like organisms (BALOs) was performed. It was based on the characterization of 71 strains and on all consequent $16 \mathrm{~S}$ rRNA gene sequences available in databases, including clones identified by data-mining, totalling 120 strains from very varied biotopes. Amplified rDNA restriction analysis (ARDRA) accurately reflected the diversity and phylogenetic affiliation of BALOs, thereby providing an efficient screening tool. Extensive phylogenetic analysis of the $16 \mathrm{~S}$ rRNA gene sequences revealed great diversity within the Bdellovibrio (>14\% divergence) and Bacteriovorax (>16\%) clades, which comprised nine and eight clusters, respectively, exhibiting more than $3 \%$ intra-cluster divergence. The clades diverged by more than $20 \%$. The analysis of conserved $16 \mathrm{~S}$ rRNA secondary structures showed that Bdellovibrio contained motifs atypical of the $\delta$-Proteobacteria, suggesting that it is ancestral to Bacteriovorax. While none of the Bdellovibrio strains were of marine origin, Bacteriovorax included separate soil/freshwater and marine-specific groups. On the basis of their extensive diversity and the large distance separating the groups, it is proposed that Bacteriovorax starrii be placed into a new genus, Peredibacter gen. nov., with Peredibacter starrii $\mathrm{A} 3.12^{\top}$ $\left(=\right.$ ATCC $15145^{\top}=$ NCCB $\left.72004^{\top}\right)$ as its type strain. Also proposed is a redefinition of the Bdellovibrio and the Bacteriovorax-Peredibacter lineages as two different families, i.e. 'Bdellovibrionaceae' and a new family, Bacteriovoracaceae. Also, a re-evaluation of oligonucleotides targeting BALOs is presented, and the implications of the large diversity of these organisms and of their distribution in very different environments are discussed.
\end{abstract}

\section{INTRODUCTION}

The obligate Gram-negative predatory bacteria belonging to the Bdellovibrio-and-like organisms (BALOs) are ubiquitously found in soil, in association with plant roots, in sea water, fresh water, biofilms and sewage (Jurkevitch et al., 2000; Varon \& Shilo, 1980; Williams et al., 1995). They were recently detected in the faeces of animals and humans (Schwudke et al., 2001). BALOs exhibit a unique biphasic

Abbreviations: ARDRA, amplified rDNA restriction analysis; BALO, Bdellovibrio-and-like organism.

The GenBank/EMBL/DDBJ accession numbers for the 16S rRNA gene sequences determined in this study are AY294207-AY294225.

Details of sequences of environmental clones exhibiting homology to BALOs, and 16S rRNA secondary-structure models, are available in IJSEM Online. life cycle in which a free-swimming cell infects the periplasmic space of a Gram-negative prey. Thereafter, the intracellular predator grows into a filament from which, at a later stage, progeny cells differentiate, lyse the host cell and start a new cycle (Jurkevitch, 2000). The molecular basis of this biphasic cycle and the determinants of the prey range (which varies greatly between BALO isolates) are unknown.

BALOs consist of two poorly defined genera, Bdellovibrio and Bacteriovorax (Baer et al., 2000), which are affiliated with the $\delta$-Proteobacteria (Woese, 1987). Recently, the classification of these two genera in the family 'Bdellovibrionaceae' under the order 'Bdellovibrionales' was proposed (Garrity et al., 2002). To date, only three BALO species have been defined: Bdellovibrio bacteriovorus, Bacteriovorax stolpii and Bacteriovorax starrii (Baer et al., 2000; Seidler et al., 1972). 
Although BALOs were discovered 40 years ago (Stolp \& Starr, 1963), and earlier works have yielded an important understanding of their fascinating cellular and physiological capabilities, we still know little of the extent of their diversity, their evolutionary history is not resolved, and our knowledge of their taxonomy remains fragmentary. Knowledge acquired by studying these aspects of BALO biology would certainly help in the development of new approaches for ecological, physiological and genome-based studies, as well as enabling a better assessment of their role in nature, which is still only rather poorly understood.

Previous studies of the phylogeny of BALOs (Baer et al., 2000; Donze et al., 1991; Jurkevitch et al., 2000; Schwudke et al., 2001; Snyder et al., 2002) were mostly restricted to certain habitats, made use of partial 16S rRNA gene sequences and were all based on a limited number of BALO strains (up to 33). Hence, a comprehensive study of BALO phylogeny based on the analysis of $16 \mathrm{~S}$ rRNA gene sequences from predatory bacteria originating from very varied habitats is needed to enable a better classification of these organisms. Such a study could then be used as a framework for the reconstruction of their natural history.

To achieve these goals, BALO strains originating from various habitats and geographical zones were analysed using the $16 \mathrm{~S}$ rRNA gene as a phylogenetic marker. Using previously published BALO $16 \mathrm{~S}$ rRNA gene sequences (Baer et al., 2000; Jurkevitch et al., 2000; Schwudke et al., 2001; Snyder et al., 2002) and sequence data available from environmental 16S rRNA gene clone libraries, we analysed the accumulated data from 120 BALO strains.

Our results reveal the very large diversity of BALOs and provide support for the definition of a new genus and for the reclassification of BALOs into two families. We also propose a putative scenario for the complex natural history of these organisms. Consequences for culture-independent studies of BALOs are presented together with a discussion of the implications of these results in a broader microbial ecological context.

\section{METHODS}

Bacterial strains, isolation procedure, media and maintenance. The BALO isolates grown in the laboratory and their habitats are listed in Table 1. BALOs were isolated from the environment on double-layer agar as described previously (Jurkevitch et al., 2000), except in the cases of freshwater and sewage isolates, for which $250 \mathrm{ml}$ samples were centrifuged at $27000 \mathrm{~g}$ for $20 \mathrm{~min}$ at $4{ }^{\circ} \mathrm{C}$ or homogenized and centrifuged at $800 \mathrm{~g}$ for $5 \mathrm{~min}$, respectively, then processed like the samples from other habitats.

Media, maintenance and growth conditions for BALO and prey cultures were as described previously (Jurkevitch et al., 2000), except for BALO strains PNEc1, PNEc2 and PNEc3, which were grown at $18^{\circ} \mathrm{C}$. The presence of very active, swimming, small, usually vibrioid cells and interactions with prey cells, as observed by using phasecontrast microscopy, established that the lysates obtained from all the plaques tested resulted from BALO-predatory activity.
Amplification of the 16S rRNA gene from BALO isolates. To remove residual prey but keep predatory cells, late-stage BALOinduced lysates were filtered $(0.45 \mu \mathrm{m}$ pore size), centrifuged at $10000 \mathrm{~g}$ for $10 \mathrm{~min}$ and resuspended in sterile double-distilled water. The suspensions were subjected to three cycles of freezing in liquid nitrogen followed by $3 \mathrm{~min}$ of heating in boiling water, cooled on ice and $10 \%$ DMSO added. BALO-specific primer $842 \mathrm{R}$ (Jurkevitch \& Ramati, 2000) was used in conjunction with Bacteriadomain-targeted primer 63F (Marchesi et al., 1998), to yield an approximately $800 \mathrm{bp}$ fragment of the 16S rRNA gene. When no product could be obtained, Bacteria-domain-targeted primer 907R (Teske et al., 1996) was used instead of primer 842R. In that case, the lysates were filtered twice through $0.45 \mu \mathrm{m}$ membranes to ensure that no prey DNA would be amplified. Also, the 16S rRNA gene of the prey in pure culture was similarly amplified.

Amplification was performed as described previously (Jurkevitch et al., 2000), apart from the addition of $12.5 \mu \mathrm{g}$ bovine serum albumin per $50 \mu \mathrm{l}$ reaction. Amplification products were purified using the High Pure PCR purification kit (Roche Molecular Biochemicals) prior to further analysis.

Amplified rDNA restriction analysis (ARDRA). To select the most distinguishing restriction enzymes, all available BALO 16S rRNA gene sequences were subjected to simulated digestion with almost all commercially available restriction enzymes. Three enzymes, HeaIII, HinfI and RsaI, were selected. EcoRI was used for further analysis of specific groups. Each PCR product (approx. $15 \mu \mathrm{l}$ ) was separately digested with each restriction enzyme according to manufacturers' instructions. Separation of the digested PCR fragments was performed by electrophoresis in $3 \%(\mathrm{w} / \mathrm{v})$ NuSieve GTG agarose (FMC) or in $2.5 \%(\mathrm{w} / \mathrm{v})$ agarose gel in TAE buffer $(40 \mathrm{mM}$ Tris/ acetate, $1 \mathrm{mM}$ EDTA) containing $0 \cdot 5 \mu \mathrm{g}$ ethidium bromide $\mathrm{ml}^{-1}$.

Amplification products obtained with prey cultures were analysed by ARDRA and the resulting patterns were compared with those of BALO products obtained with the Bacteria-domain-targeted primer pair, to ensure that the latter originated from the predators alone.

The combination of the restriction patterns defined the ARDRA group affiliation of each strain. Restriction maps were inferred from comparison of the resulting fragment patterns with the available sequences. Twenty-nine different restriction sites were identified. Restriction-site differences were analysed by using the maximumlikelihood approach for analysis of restriction sites (Felsenstein, 1992), available with the PHYLIP package (J. Felsenstein, University of Washington, Seattle).

DNA sequencing and phylogenetic analysis. The 16S rRNA gene of selected isolates was first partially sequenced (450-750 bp). When sequences diverged from any other known sequence by more than $1.5 \%$, the gene was sequenced along almost its entire length (more than $1400 \mathrm{bp}$ ), using internal primers (Jurkevitch et al., 2000) or new custom-designed primers, as needed for primer walking. DNA sequencing was carried out with an ABI Prism 337 DNA sequencer (Applied Biosystems).

$16 \mathrm{~S}$ rRNA gene sequences were added to the rRNA gene sequence database of the ARB phylogenetic program package (Strunk et al., 1999). The ARB-ALIGN tool was used for sequence alignment. The resulting alignments were checked and corrected manually on the basis of both primary and secondary structure considerations.

Framework phylogenetic trees were constructed on the basis of positions 69-1404 (Escherichia coli numbering) of the BALO 16S rRNA gene sequences, using the ARB neighbour-joining, parsimony and maximum-likelihood methods, in combinations with different filters (excluding different degrees of variable positions), different 
Table 1. BALO strains used in this study and their ARDRA group

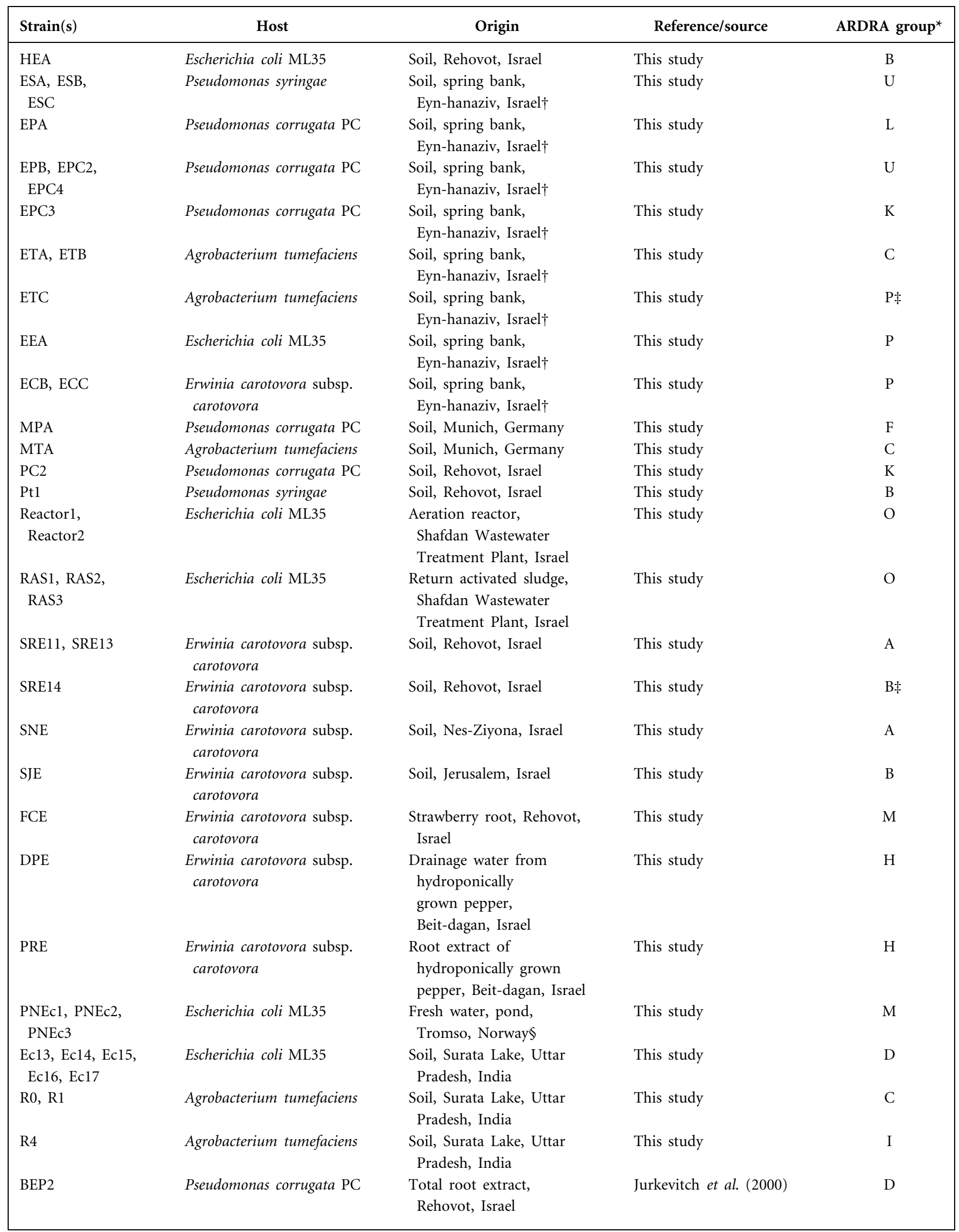


Table 1. cont.

\begin{tabular}{|c|c|c|c|c|}
\hline Strain(s) & Host & Origin & Reference/source & ARDRA group ${ }^{*}$ \\
\hline SRP8E & Pseudomonas corrugata $\mathrm{PC}$ & Soil, Rehovot, Israel & Jurkevitch et al. (2000) & A \\
\hline SRP20 & Pseudomonas corrugata PC & Soil, Rehovot, Israel & Jurkevitch et al. (2000) & A \\
\hline SRE8 & $\begin{array}{l}\text { Erwinia carotovora subsp. } \\
\text { carotovora }\end{array}$ & Soil, Rehovot, Israel & Jurkevitch et al. (2000) & A \\
\hline TRA2 & Agrobacterium tumefaciens & $\begin{array}{l}\text { Total root extract, } \\
\text { Rehovot, Israel }\end{array}$ & Jurkevitch et al. (2000) & I \\
\hline $\mathrm{CHI}$ & Escherichia coli $\mathrm{AB} 6$ & $\begin{array}{l}\text { Fresh water, Murcia, } \\
\text { Spain }\end{array}$ & $\begin{array}{l}\text { Kindly donated by F. Torrella } \\
\text { (Universidad de Murcia, Spain) }\end{array}$ & $A \ddagger$ \\
\hline $\mathrm{F} 2$ & Escherichia coli AB6 & Fresh water, Murcia, Spain & Kindly donated by F. Torrella & $\mathrm{O}$ \\
\hline ARL-1, ARL-2 & Pseudomonas fluorescens & Sewage, Pushchino, Russia & $\begin{array}{l}\text { Kindly donated by A. Afinogenova } \\
\text { (previously at the Russian Academy } \\
\text { of Sciences, Pushchino, Russia) }\end{array}$ & G \\
\hline ARL-11, B-608 & $\begin{array}{l}\text { Erwinia carotovora subsp. } \\
\text { carotovora }\end{array}$ & Sewage, Pushchino, Russia & Kindly donated by A. Afinogenova & A \\
\hline B-610 & Escherichia coli $\mathrm{K}-12$ & Sewage, Pushchino, Russia & Kindly donated by A. Afinogenova & $\mathrm{A}$ \\
\hline ARL-12 & Alcaligenes faecalis & Oka River, Russia & Kindly donated by A. Afinogenova & $\mathrm{H}$ \\
\hline $\mathrm{P}$ & Escherichia coli $\mathrm{K}-12$ & $\begin{array}{l}\text { Fresh water, Pushchino } \\
\text { Pond, Russia }\end{array}$ & Kindly donated by A. Afinogenova & A \\
\hline $\mathrm{L}$ & Pseudomonas fluorescens & $\begin{array}{l}\text { Sewage water, St } \\
\text { Petersburg, Russia }\end{array}$ & Kindly donated by A. Afinogenova & G \\
\hline Viet & Escherichia coli B & $\begin{array}{l}\text { Anaerobic layer, rice } \\
\text { field, Vietnam }\end{array}$ & Kindly donated by A. Afinogenova & A \\
\hline NM1 & Proteus mirabilis & Chicken gut, Germany & Schwudke et al. (2001) & $\mathrm{A}$ \\
\hline Pf & Proteus mirabilis & Horse gut, Germany & Schwudke et al. (2001) & A \\
\hline S1 & Proteus mirabilis & Human gut, Germany & Schwudke et al. (2001) & A \\
\hline SD1 & Citrobacter freundii & Sewage, Leipzig, Germany & Schwudke et al. (2001) & $\mathrm{N}$ \\
\hline $100^{\mathrm{T}}$ & Erwinia amylovora & Soil, California, USA & Stolp \& Starr (1963) & A \\
\hline 109D & Escherichia coli ML35 & Sewage, California, USA & Kindly donated by A. Afinogenova & A \\
\hline $109 \mathrm{~J}$ & Escherichia coli ML35 & Sewage, California, USA & $\begin{array}{l}\text { American Type Culture Collection } \\
\text { (Manassas, VA, USA) }\end{array}$ & A \\
\hline $\mathrm{W}$ & Rhodospirillum rubrum & Sewage, Freiburg, Germany & American Type Culture Collection & $\mathrm{E}$ \\
\hline $\mathrm{Uki}^{\mathrm{T}}$ & Escherichia coli B & Soil, Kentucky, USA & American Type Culture Collection & M \\
\hline $\mathrm{A} 3.12^{\mathrm{T}}$ & Pseudomonas fluorescens & Soil, California, USA & Stolp \& Starr $(1963)$ & $\mathrm{K}$ \\
\hline $6-5-S$ & Escherichia coli ML35 & London, Ontario, Canada & Kindly donated by A. Afinogenova & A \\
\hline JSS & Caulobacter crescentus & $\begin{array}{l}\text { Sewage, London, Ontario, } \\
\text { Canada }\end{array}$ & $\begin{array}{l}\text { Kindly donated by S. Koval (University } \\
\text { of Western Ontario, Canada) }\end{array}$ & $\mathrm{J}$ \\
\hline
\end{tabular}

${ }^{*}$ See Fig. 1 and Table 2 for ARDRA patterns.

$\dagger$ Isolates retrieved in the same isolation event: ESA, ESB, ESC, EPA, EPB, EPC2, EPC3, EPC4, ETA, ETB, ETC, EEA, ECB, ECC.

$\ddagger$ In some cases, complex restriction patterns were exhibited (i.e. the total length of the restriction pattern bands was above the expected 800 bp) with enzyme HaeIII (SRE14), HinfI (CHI) or with both enzymes (ETC).

§Isolated and grown at $18^{\circ} \mathrm{C}$.

corrections and different outgroups. The consistency of the tree was also verified by bootstrapping $(n=1000)$ for neighbour-joining and parsimony. Shorter sequences (less than $1100 \mathrm{bp}$ ) were then added to the tree using the parsimony and maximum-likelihood methods. It was verified that these additions did not alter the overall tree structure.

Identification of similarity to BALO sequences in environmental clones. 16S rRNA gene sequences from environmental clone libraries appearing in BLAST (http://www.ncbi.nih.gov/blast/) and FASTA (http://www.ebi.ac.uk/fasta33/) in similarity searches using BALO sequences were included in the phylogenetic trees as described above. Sequences for which phylogenetic positions could not be unambiguously determined, because of their short length or their large divergence from other sequences, were not included in our analysis. In total, 11 almost-complete sequences and nine shorter sequences from environmental clones were selected (see Table A in IJSEM Online). Nine of these sequences exhibited similarity to the Bdellovibrio lineage and 11 showed similarity to the Bacteriovorax lineage.

Identification of differences in evolutionary rates as a source of uncertainty. We used the following criteria to identify differences in evolutionary rates and the long-branch attraction effect (Philippe \& Laurent, 1998) on selected branches in our phylogenetic trees: (1) with a lower filter, the branch tended to move towards the root; (2) the more distant the outgroup used to root the 
tree, the further the branch moved towards the root; (3) with parsimony or neighbour-joining as treeing methods, the branch tended to move towards the root, in comparison with maximum likelihood; and (4) the sequence under analysis shared conserved insertions or deletions (i.e. rare genomic changes) with sequences on other distantly related branches (the Hennigian approach; Philippe \& Laurent, 1998).

Analysis of 16S rRNA secondary structure. Secondary structures were deduced using the European database on small-subunit rRNA (Wuyts et al., 2002), the Comparative RNA Web Site (Cannone et al., 2002) and previous work (Schwudke et al., 2001). The results were confirmed by computational investigation using MFOLD (Mathews et al., 1999).

Nucleotide sequence accession numbers. Sequences determined during this study are available from GenBank under accession numbers AY294207-AY294225. Environmental clone sequences are available in the GenBank database under accession numbers AY177783, AY168736, AF445705, AF445695, AF385539, AF332269, AF314449, AF314450, AY157087, AJ290009, AJ290002, AF030776, AF030781, AJ240999, AB054175, AJ518802, AF211265, AF392700, AF431402 and AY341110. Other BALO isolate sequences used in this study are available from GenBank under accession numbers AF084852, AF084850, M34125, AF263833, AF263832, AF148938AF148941, AJ278145, AJ288899, AJ292759, AJ292760, AJ292518, AJ278146, AY094106-AY094131 and AF084851-AF084863.

(a)
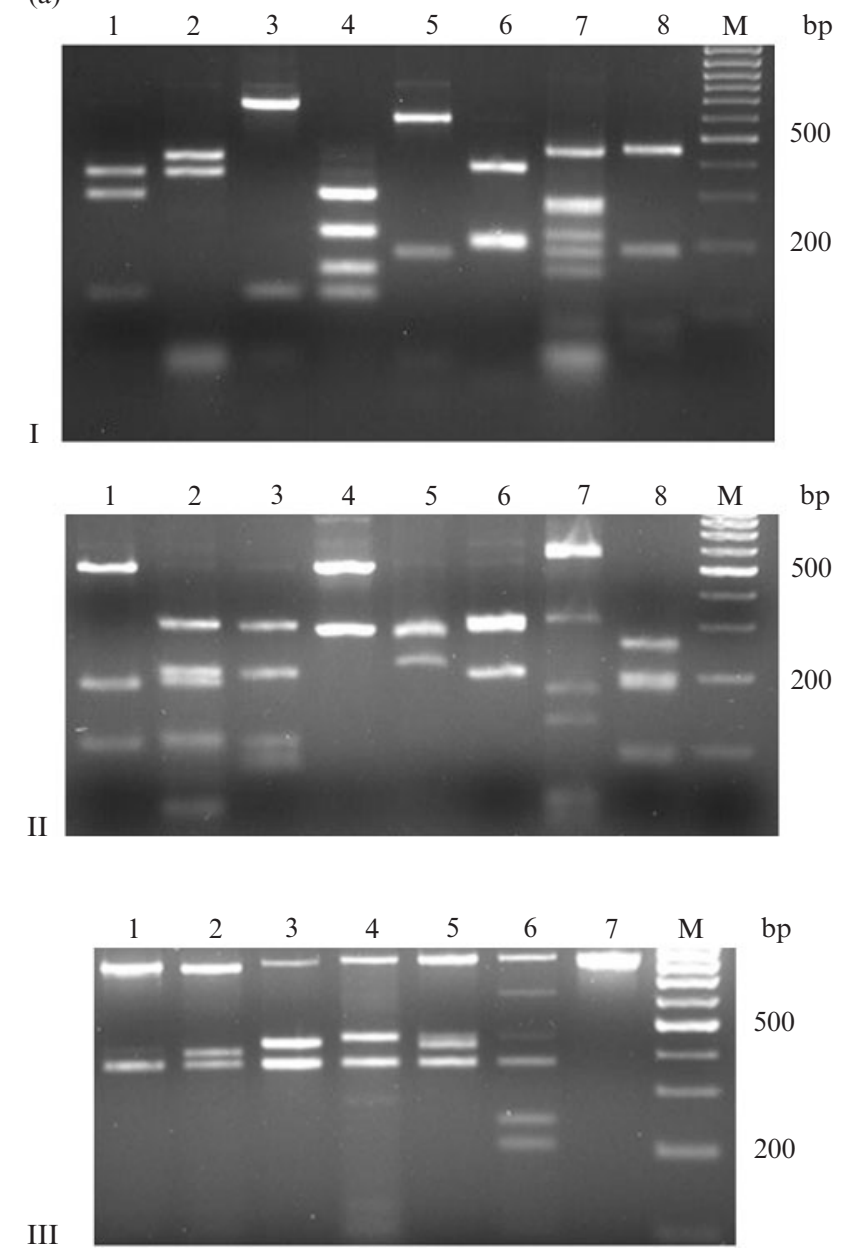

Clone descriptions and corresponding accession numbers are given in Table A in IJSEM Online.

\section{RESULTS AND DISCUSSION}

All previously available BALO $16 \mathrm{~S}$ rRNA sequence data, as well as data from new isolates, but excluding short and ambiguous sequences, were used in this study. Included in this were data for 71 isolates grown in the laboratory, sequence data from another 29 isolates (mostly published) found in the GenBank database, and 20 sequences from environmental clones, which were identified by data-mining.

\section{ARDRA}

Seventy-one BALO isolates (Table 1), originating from soil, root extracts, fresh water, sewage and animal faecal samples, spanning geographical regions from the tropics to almost arctic areas, and isolated using various Gram-negative bacteria as prey, were used to construct a phylogenetic screen using ARDRA. Restriction profiles, most of which are presented in Fig. 1(a), were obtained using HaeIII, HinfI and RsaI. Combination of these profiles yielded 17 different ARDRA groups (Table 1 and Table 2). An in-silico analysis of another 18 sequences of BALOs isolated revealed four (b)

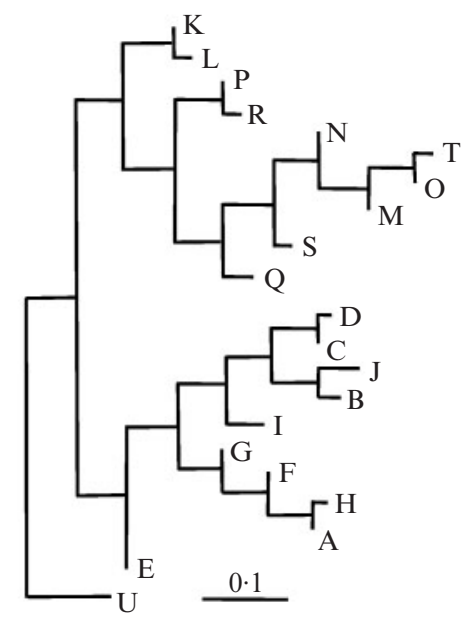

Fig. 1. (a) Restriction patterns of amplified 16S rRNA gene fragments of BALOs after digestion with HeallI (I), HinfI (II) and Rsal (III). M, $100 \mathrm{bp}$ molecular size marker. The combination of the patterns defined the different ARDRA groups. (b) Dendrogram of relatedness of the ARDRA groups. The tree was constructed using the maximum-likelihood method (RestML) based on the presence or absence of each restriction site in the different ARDRA groups. Bar, 10\% estimated differences. 
Table 2. Patterns obtained by ARDRA of BALOs

\begin{tabular}{|c|c|c|c|c|c|}
\hline \multirow[t]{2}{*}{ Group } & \multicolumn{3}{|c|}{$\begin{array}{l}\text { ARDRA banding } \\
\text { pattern* }\end{array}$} & \multicolumn{2}{|c|}{$\begin{array}{l}\text { Number of } \\
\text { isolates }\end{array}$} \\
\hline & HaeIII & Hinf I & RsaI & This study & From database \\
\hline A & 1 & 1 & 1 & 19 & 3 \\
\hline B & 1 & 3 & 2 & 4 & - \\
\hline $\mathrm{C} \dagger$ & 2 & 2 & 1 & 5 & 1 \\
\hline $\mathrm{D} \dagger$ & 2 & 2 & 1 & 6 & 1 \\
\hline E & $10 \ddagger$ & 1 & 1 & 1 & - \\
\hline $\mathrm{F}$ & 3 & 1 & 1 & 1 & - \\
\hline G & 1 & 2 & 2 & 3 & - \\
\hline $\mathrm{H}$ & 1 & 1 & 2 & 3 & 1 \\
\hline I & $9 \ddagger$ & $9 \ddagger$ & 1 & 2 & - \\
\hline $\mathrm{J}$ & 4 & 4 & 1 & 1 & - \\
\hline K & 5 & 5 & 3 & 3 & 1 \\
\hline $\mathrm{L}$ & 5 & 5 & 7 & 1 & - \\
\hline M & 6 & 6 & 4 & 5 & - \\
\hline $\mathrm{N}$ & 6 & 6 & 5 & 1 & 1 \\
\hline $\mathrm{O}$ & 6 & 6 & 6 & 6 & - \\
\hline $\mathrm{P} \S$ & 7 & 7 & 2 & 4 & - \\
\hline Q & $11 \ddagger$ & $10 \ddagger$ & $8 \ddagger$ & - & 5 \\
\hline $\mathrm{R}$ & $12 \ddagger$ & 6 & $9 \ddagger$ & - & 2 \\
\hline S & $13 末$ & 6 & $10 \ddagger$ & - & 2 \\
\hline $\mathrm{T}$ & 6 & 6 & $11 \ddagger$ & - & 1 \\
\hline U\$ & 8 & 8 & 7 & 6 & - \\
\hline
\end{tabular}

${ }^{*}$ Numbers in columns relate to the lanes in Fig. 1(a). Groups Q, R, S and $\mathrm{T}$ are based on in-silico digestions with sequences retrieved from GenBank.

$\dagger$ Distinguishable by restriction with EcoRI (for patterns, see Jurkevitch et al., 2000).

‡Lanes not shown in Fig. 1(a).

\$Amplicon obtained using primer 907R instead of $842 \mathrm{R}$.

( Q, R, S, T) additional ARDRA groups. Groups Q, R and S were exclusively composed of marine strains.

On the basis of these data, a dendrogram was constructed (Fig. 1b). Two clades consisting of groups $\mathrm{A}-\mathrm{J}$ and $\mathrm{K}-\mathrm{T}$, which completely overlapped the Bdellovibrio and the Bacteriovorax lineages and their internal complexities, respectively (see below), could be calculated. ARDRA group U formed a separate group (Fig. 1b). The taxonomic resolution of ARDRA is considered to be at the genus or species level (Heyndrickx et al., 1996; Vandamme et al., 1996) but, to date, BALOs have only been assigned to two genera and three species.

Fourteen strains isolated from Eyn-hanaziv soil in one isolation event (Table 1) belonged to five different ARDRA groups and were affiliated to Bdellovibrio, Bacteriovorax starrii, Bacteriovorax stolpii and to the unclassified U group, indicating that the same habitat supports a great diversity of BALOs.

\section{5 rRNA gene sequence and phylogenetic analyses}

The 16S rRNA genes of representative strains from different ARDRA groups were sequenced. In some cases, a number of strains from the same group but of different origins were selected to evaluate the resolution of ARDRA. Also included in the phylogenetic analysis were all BALO sequences available in databases and 20 sequences of environmental clones identified by similarity searches.

When long-branch attraction criteria were applied, a number of branches, most of which were in the Bdellovibrio lineage, behaved as if large differences in evolutionary rate existed between them and the rest of the lineage. Therefore, their phylogenetic positions varied considerably with different combinations of treeing methods, filters and outgroups. Strains included in ARDRA group $U$ did not belong to either the Bdellovibrio or the Bacteriovorax lineage. Strain JSS clustered within the Bdellovibrio lineage but exhibited a unique morphology. Both will be discussed in other publications (Y. Davidov \& E. Jurkevitch, unpublished).

\section{Bdellovibrio phylogeny}

Forty-two $16 \mathrm{~S}$ rRNA gene sequences were included in the analysis of the Bdellovibrio clade (Fig. 2a). Bdellovibrio isolates and environmental clones originated from soil, roots, fresh water, sewage and faeces, but none were from marine environments. Using different treeing methods, filters and outgroups, nine stable monophyletic clusters were identified within the Bdellovibrio lineage (Fig. 2a). Sequence similarity between members of the different clusters was always below $97 \%$, while sequence similarity between members of the same cluster was always above $97 \cdot 5 \%$. The definition of a bacterial species requires a polyphasic approach (Rossello-Mora \& Amann, 2001; Vandamme et al., 1996). However, strains that are more than 3\% divergent in their $16 \mathrm{~S}$ rRNA gene sequences are nearly always members of different species (Stackebrandt \& Goebel, 1994). The larger distances observed between the clusters $(\geqslant 3 \%)$ suggested that each represents at least one putative species. Strains that are less than $3 \%$ divergent may or may not be members of different species (Fox et al., 1992; Cohan, 2002), so more data are needed to determine in-cluster systematic affiliations. Although the phylogenetic positions of environmental strains PHOS-HC31, PHOS-HE81 and WB-66, represented by short ( $\leqslant 600 \mathrm{bp}$ ) sequences, could not be determined unequivocally (Fig. 2a), the degree of their divergence from other sequences supported a putative affiliation to currently unrecognized additional clusters. Despite the unambiguous strain composition of each cluster, and a stable internal structure in most, the relative positions of the clusters were often uncertain. The following description of the clusters supports the information obtained by ARDRA and by sequencing (Fig. 3a). 
Cluster 1 was the largest BALO cluster, including 32 isolates. It comprised the species Bdellovibrio bacteriovorus and some of the first BALOs isolated (e.g. strain $100^{\mathrm{T}}$ ) and 109J, the best-studied BALO (Stolp \& Starr, 1963). Although subgroups could be differentiated, the overall internal heterogeneity was below $2 \cdot 2 \%$. Whole genome DNA-DNA hybridization data are available for five of the strains in this cluster: $100^{\mathrm{T}}, 109 \mathrm{~J}, \mathrm{E}, \mathrm{Ox} 92$ and 2484Se2 (Baer et al., 2000). A high degree of homology (75-100\%) was observed between the four former strains, while lower values (33$55 \%$ ) were obtained between strain $2484 \mathrm{Se} 2$ and the four other strains (Baer et al., 2000). These results are in accordance with the relative positions of these strains, as determined by $16 \mathrm{~S}$ rRNA gene sequence analysis (Fig. 2a). On the basis of the standard of $70 \%$ homology adopted for determining whether two strains should be considered as different species (Wayne et al., 1987), the data supported the existence of more than one species within this cluster. Isolates found in this group varied in origin (Table 1). However, none of the environmental clones clustering with BALOs belonged to this group, suggesting a bias due to the isolation method employed. Cluster 2 consisted of six isolates and one environmental clone from soil and fresh water. The long distance separating it from its closest neighbour, which may be due to different evolutionary rates, hampered an unambiguous resolution of its position. All of the six strains constituting cluster 3 were isolated on Agrobacterium tumefaciens from four different soils. Clusters 4 and 5 were neighbouring clusters and included strains originating from sewage and soil, respectively. Strain $\mathrm{W}$, the sole strain in cluster 4 , is the only recognized BALO isolate exhibiting a resting stage (Hoeniger et al., 1972). It is not currently known if the seven strains in neighbouring cluster 5 also exhibit this property. Clusters 6 and 7 are represented by a unique isolate and an environmental clone, respectively, the latter originating from an arseniteoxidizing biofilm. Two environmental clones obtained from hot-spring travertine depositions in a $55^{\circ} \mathrm{C}$, slightly basic water column (G. Bonheyo, personal communication) formed cluster 8 . These environmental sequences represented additional, hitherto unrecognized Bdellovibrio groups, but predatory behaviour could not be confirmed because the organisms were not isolated. These sequences showed clear signs of unusually rapid evolution and of long-branch attraction. One soil strain and one plant-root strain, each from different geographical origins, but both having been isolated on A. tumefaciens, constituted cluster 9. No identifiable phenotypic differences in predation dynamics, plaque development or predator-prey interactions could be detected between the members of this phylogenetically distant cluster and other members of the Bdellovibrio clade. Using accepted standards for genus definition (Ludwig et al., 1998; Vandamme et al., 1996), clusters 1-7, 8 and 9 (Fig. 3a) may represent different genera. On the basis of its outlying phylogenetic position and unknown morphology, the inclusion of oral clone CA006 as a true BALO is tentative, although it clearly clustered with the Bdellovibrio lineage.

\section{Bacteriovorax phylogeny}

Forty-one 16S rRNA gene sequences were included in this analysis. Using different treeing methods, filters and outgroups, eight stable monophyletic clusters were identified within the Bacteriovorax lineage (Fig. 2b). Sequence similarity between members of the different clusters was always below $96 \%$. Internal cluster similarity was above $98.5 \%$, except for cluster I, in which heterogeneity was $96 \cdot 4 \%$. These eight clusters formed four stable monophyletic groups (Fig. 2b). Environmental clones HOC41 and Sva0447 may define additional, unrecognized putative Bacteriovorax groups, but because of their outlying phylogenetic and unstable position, as well as an unknown morphology, their affiliation to the BALOs is not certain. Because of the low quality of their sequences and long-branch attraction, environmental clones Adriatic33 and Adriatic91, which clearly clustered within the Bacteriovorax lineage, were not designated clusters. The following description of the clusters supports the information obtained by ARDRA and by sequencing (Fig. 3b).

Cluster I consisted of seven isolates, including Bacteriovorax stolpii $\mathrm{Uki}^{\mathrm{T}}$, and six additional environmental clones from five different samples. Isolates and clones were mainly obtained from fresh water, but also came from sewage, soil, rhizospheres and uranium mining waste. The large 16S heterogeneity $(3.6 \%)$ and the clear branching order within this cluster (Fig. 2b) showed that it may be composed of more than one species, but because other specific phenotypic or molecular characteristics were lacking, these phylotypes cannot yet be characterized as new species. The relatively high frequency of environmental clones in this cluster suggested that members of this group are more abundant than is reflected by the isolation methods. Cluster II consisted of seven freshwater and sewage isolates; together with cluster I, they formed the Uki2 $2^{\mathrm{T}}$ group (Fig. 2b).

Only marine strains were found in clusters III, IV and V. Together, they formed a monophyletic group consisting of 18 members (including clones Adriatic33 and CE46) with an inside sequence heterogeneity of more than $8 \%$ (the marine group, Fig. 2b).

Cluster VI was made up of four isolates of soil origin, and exhibited $12 \cdot 2 \%$ divergence from the closest other BALOs. Together, the Uki2 $2^{\mathrm{T}}$, marine and ETC groups formed a stable, distinct monophyletic lineage.

Clusters VII and VIII were composed of five soil isolates in total, including Bacteriovorax starrii $\mathrm{A} 3.12^{\mathrm{T}}$. These organisms formed a very distinct monophyletic group (the $\mathrm{A} 3.12^{\mathrm{T}}$ group), with an inside sequence heterogeneity of $4 \%$, and exhibited a minimal dissimilarity of more than $12.5 \%$ to the closest known group.

Since (1) the divergence separating the $\mathrm{A} 3.12^{\mathrm{T}}$ group from the other Bacteriovorax members was large, with a minimum distance of more than $12.5 \%$ and a maximum distance of more than $16 \%$, (2) they formed two separated 
(a)
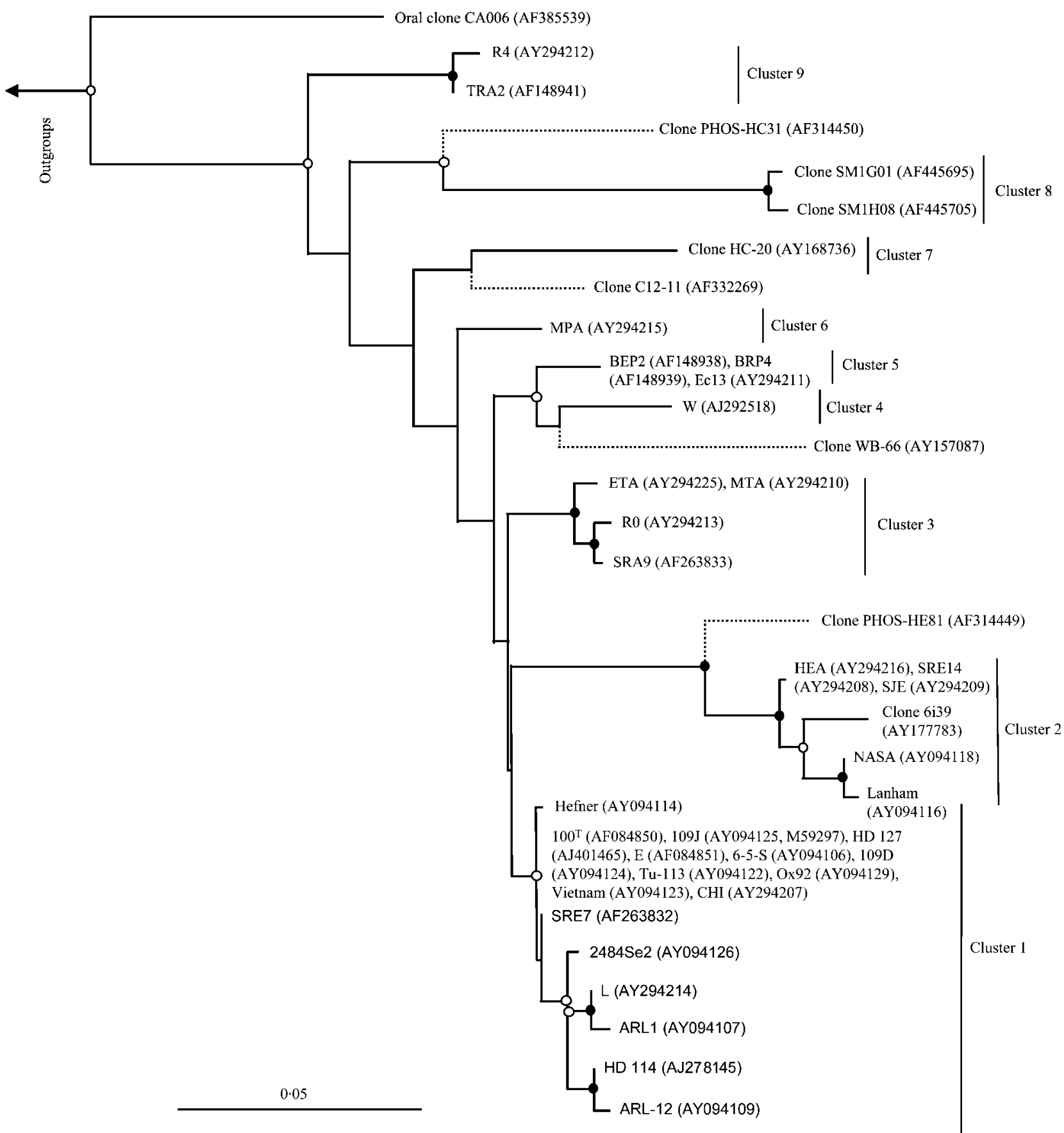

Fig. 2. Phylogenetic $16 \mathrm{~S}$ rRNA tree of the Bdellovibrio (a) and Bacteriovorax (b) lineages. The tree is based on maximumlikelihood (FastDNAml) analysis, using a $50 \%$ conservation filter. Listed beside each strain or clone name is the GenBank accession number (in parentheses). Branch points supported by parsimony bootstrap values (1000 replicates) of $>90,>75$ and $>50 \%$ are indicated by solid black, solid grey and open circles, respectively, while branch points that were not resolved (bootstrap values of $<50 \%$ ) are depicted without circles. Partial sequences $(\leqslant 600 \mathrm{bp}$ ), which did not provide sufficient information for an unequivocal phylogenetic position, are indicated by dotted lines. Bacteriovorax strains Uki $2^{\top}, A 3.12^{\top}$ and ETC were used as outgroups for treeing the Bdellovibrio lineage, while Bdellovibrio strains $100^{\top}, H E A$ and TRA2 were used as outgroups for treeing the Bacteriovorax lineage. Bars, $5 \%$ estimated sequence divergence. 


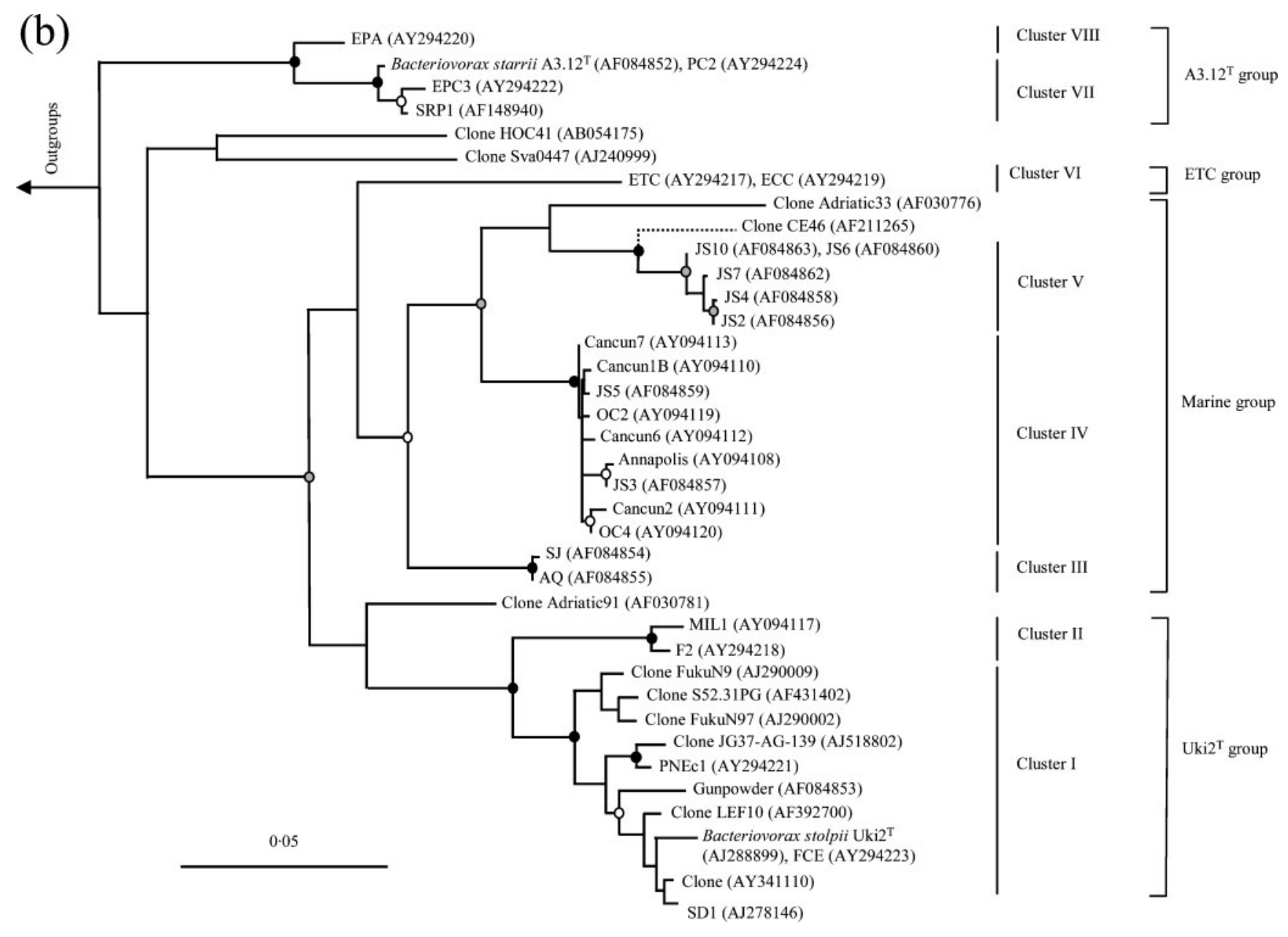

\begin{tabular}{|c|c|c|c|c|}
\hline & Cluster & $\begin{array}{c}\text { ARDRA } \\
\text { groups }\end{array}$ & $\begin{array}{c}\text { In-cluster } \\
\text { divergence } \\
(\%)\end{array}$ & $\begin{array}{c}\text { Divergence } \\
\text { with closest } \\
\text { outgroup } \\
(\%)\end{array}$ \\
\hline \multirow{5}{*}{ (a) } & $\Gamma 1$ & $\mathrm{~A}, \mathrm{G}, \mathrm{H}$ & $1 \cdot 4$ & $3 \cdot 0$ \\
\hline & -2 & B & $2 \cdot 5$ & $6 \cdot 6$ \\
\hline & -3 & C & $1 \cdot 3$ & $3 \cdot 0$ \\
\hline & $\Gamma^{4}$ & D & 0 & 3.6 \\
\hline & 25 & E & - & $4 \cdot 6$ \\
\hline \multirow{3}{*}{ Outgroups } & -6 & F & - & 3.6 \\
\hline & $\llcorner 7$ & - & - & $7 \cdot 1$ \\
\hline & -8 & - & 0.5 & 11.6 \\
\hline \multirow{3}{*}{ (b) } & -9 & I & 0.9 & 7.6 \\
\hline & Гᄃ I & $\mathrm{M}, \mathrm{N}, \mathrm{T}$ & $3 \cdot 6$ & $5 \cdot 3$ \\
\hline & ᄂ II & $\mathrm{O}$ & $1 \cdot 3$ & $5 \cdot 3$ \\
\hline \multirow{6}{*}{ Outgroups } & $\Gamma \mathrm{III}$ & $\mathrm{S}$ & $0 \cdot 7$ & 7.8 \\
\hline & L IV & $\mathrm{R}$ & $1 \cdot 4$ & $6 \cdot 8$ \\
\hline & $\mathrm{L} \mathrm{V}$ & Q & $0 \cdot 1$ & $6 \cdot 8$ \\
\hline & $-\quad$ VI & $\mathrm{P}$ & 0 & $12 \cdot 2$ \\
\hline & $\Gamma$ VII & $\mathrm{K}$ & 1.5 & $4 \cdot 0$ \\
\hline & L VIII & $\mathrm{L}$ & - & $4 \cdot 0$ \\
\hline
\end{tabular}

Fig. 3. Schematic relationships of phylogenetic clusters with ARDRA groups in the Bdellovibrio (a) and Bacteriovorax (b) lineages. The environmental clones composing clusters 7 and 8 defined two additional, different ARDRA patterns. Multifurcations indicate that a relative order could not be unambiguously determined by applying different treeing methods or outgroups. monophyletic groups with high bootstrap values, (3) the 16S rRNA secondary structure formed at positions 184-193 in this group was atypical of Bacteriovorax (Schwudke et al., 2001; and see below), and (4) the DNA-DNA hybridization values obtained between strains Bacteriovorax starrii $\mathrm{A} 3.12^{\mathrm{T}}$ and Bacteriovorax stolpii $\mathrm{UKi}^{\mathrm{T}}$ were very low ( $<5 \%$; Baer et al., 2000), we propose the creation of a new genus, Peredibacter gen. nov., and Peredibacter starrii comb. nov., with $\mathrm{A} 3.12^{\mathrm{T}}$ as the type strain.

Using accepted standards for genus definition (Ludwig et al., 1998; Vandamme et al., 1996), clusters I-II, III-V and VI (Fig. 3b) may signify additional different genera.

Many marine-specific and some freshwater-specific bacterial phylogenetic clusters have been proposed (Giovannoni et al., 1990; Glöckner et al., 2000). Phylogenetic analysis of the Bacteriovorax lineage suggested the existence of a separate marine group. Members of the Uki ${ }^{\mathrm{T}}$ group (Fig. 2b) were isolated from soil rhizospheres but especially from freshwater and sewage environments. The position of the marine group compared to the ETC and the $\mathrm{A} 3.12^{\mathrm{T}}$ groups, which are solely composed of soil isolates, suggested that BALOs adapted from soil to fresh water and then to marine environments. The fact that all the Bdellovibrio 
strains known to date originated from terrestrial environments also lends support to that assumption (see below).

BALO clusters comprising at least one isolated strain will be characterized further to describe the putative new species and genera identified in this work.

\section{ARDRA versus sequencing}

The results obtained by ARDRA showed that by using an appropriate combination of restriction enzymes and primers this relatively rapid method enabled an efficient screening of BALO isolates that accurately reflected the diversity and phylogeny of these organisms. Members of the same ARDRA group always exhibited sequence heterogeneity of less than $3 \cdot 2 \%$. There was a complete overlap between the ARDRA groups and the 16S sequence clusters, except in the cases of clusters 1 and I, both of which consisted of three ARDRA groups (Fig. 3).

\section{BALO phylogeny}

The analysis confirmed the conclusion of previous studies, namely that Bdellovibrio and Bacteriovorax are members of the $\delta$-Proteobacteria (Jurkevitch et al., 2000; Snyder et al., 2002; Woese, 1987). However, neither of these groups formed a stable association with any other $\delta$ or $\varepsilon$-proteobacterial groups (Fig. 4). Most of the $\delta / \varepsilon$ Proteobacteria orders form clear clades ('Desulfobacterales' are a prominent exception; Castro et al., 2000). Nevertheless, the relative position of the clades is not resolved. Each of the Bdellovibrio and Bacteriovorax lineages formed a very stable clade (using different treeing methods, bootstrap values were always above $90 \%$ ), but together they did not form a monophyletic group, and the phylogenetic distance between them was large (>20\%). Long-branch attraction appeared to contribute to the uncertainty in the relative positions of the BALO clades. While the Bacteriovorax lineage clearly clustered with other $\delta$-Proteobacteria, the Bdellovibrio lineage seemed to be distinct, indicating a very early split or a fast evolutionary rate. This is in accordance with the finding that, by omitting Bdellovibrio from the $\delta$-Proteobacteria analysis, bootstrap values supporting the $\delta$-Proteobacteria as a monophyletic clade were improved considerably (Wright et al., 1997). When analysed by BLAST or FASTA, the best hits obtained with Bdellovibrio $16 \mathrm{~S}$ rRNA gene sequences outside their own clade mostly belonged to the $\alpha$-Proteobacteria, providing yet another indication of the separation of the two BALO lineages and the occurrence of an early split of Bdellovibrio from other $\delta$-Proteobacteria.

The occurrence of BALO sequences forming a separate cluster (Bdellovibrio cluster 8) in libraries of 16S rRNA from hot-springs bacteria suggested that the bacterial predators can also be active in thermophilic environments. Psychrophilic BALOs were represented by Bacteriovorax stolpii strains PNEc1, PNEc2 and PNEc 3, and by clone Sva0447, isolated from a pond in Northern Norway, and from arctic marine sediments, respectively. BALOs (or BALO sequences) have now been isolated from habitats covering a wide range of environmental conditions. The large phylogenetic diversity uncovered suggested that the actual variety of BALOs may be orders of magnitude above that which is known at present, as only very few culturable prey have been used for their isolation and many more habitats have yet to be probed. Moreover, as BALOs are not dominant populations, BALO clones are seldom found in environmental $16 \mathrm{~S}$ rRNA gene libraries. DNA extraction biases may be another reason for the low occurrence of BALOs in cultivation-independent surveys: under starvation conditions in a marine environment, the formation of stable bdelloplasts with increased stress resistance was observed (Sanchez-Amat \& Torrella, 1990), and these bdelloplasts may be more recalcitrant to DNA extraction. Although still sporadic, the examination of cultivationindependent data as opposed to cultivation-dependent data suggested that isolation-based studies were biased towards or against certain clusters (e.g. Bdellovibrio cluster 1 and Bacteriovorax cluster I, respectively). BALO groups that can grow at the expense of a commonly used prey such as Escherichia coli were probably over-represented in cultivation-based studies, while others remained undetected. Similarly, BALOs requiring 'non-standard' isolation and growth conditions (temperature, salinity, $\mathrm{pH}$, etc.) were certainly under-represented.

What are the implications of the wide distribution and great diversity of BALOs? It has been suggested (1) that marine viruses influence ecological and biogeochemical processes such as bacterial biodiversity, dynamics and species distributions, primary productivity and nutrient cycling (Fuhrman, 1999), (2) that predatory protists are major contributors to the control of microbial community structure (Jürgens et al., 1999; Ronn et al., 2002), and (3) that predation acts as a major factor driving prokaryotic diversity (Torsvik et al., 2002). As BALOs exhibit hostspecificity, a small increase in mortality induced by predation in a group of organisms may have a profound effect on the relative proportions and functions of different key species in the community. The abundance and diversity of BALOs in nature, barely investigated to date, suggest that, like to other bacterial predators, BALOs may have a large effect on the structure and dynamics of microbial communities.

Since no other known group clustered between the Bdellovibrio and Bacteriovorax lineages, and given their morphological similarity, the occurrence of common specificities such as predatory behaviour, and their peculiar life cycle, it is reasonable to hypothesize that most of these shared unique characteristics originated from the same common ancestor. Predatory behaviour, and, in particular, predatory behaviour resulting in cell invasion, is a complex trait not commonly encountered in the domain Bacteria. Close investigation of different BALO clades might provide us with new insights about the evolution of predation in 


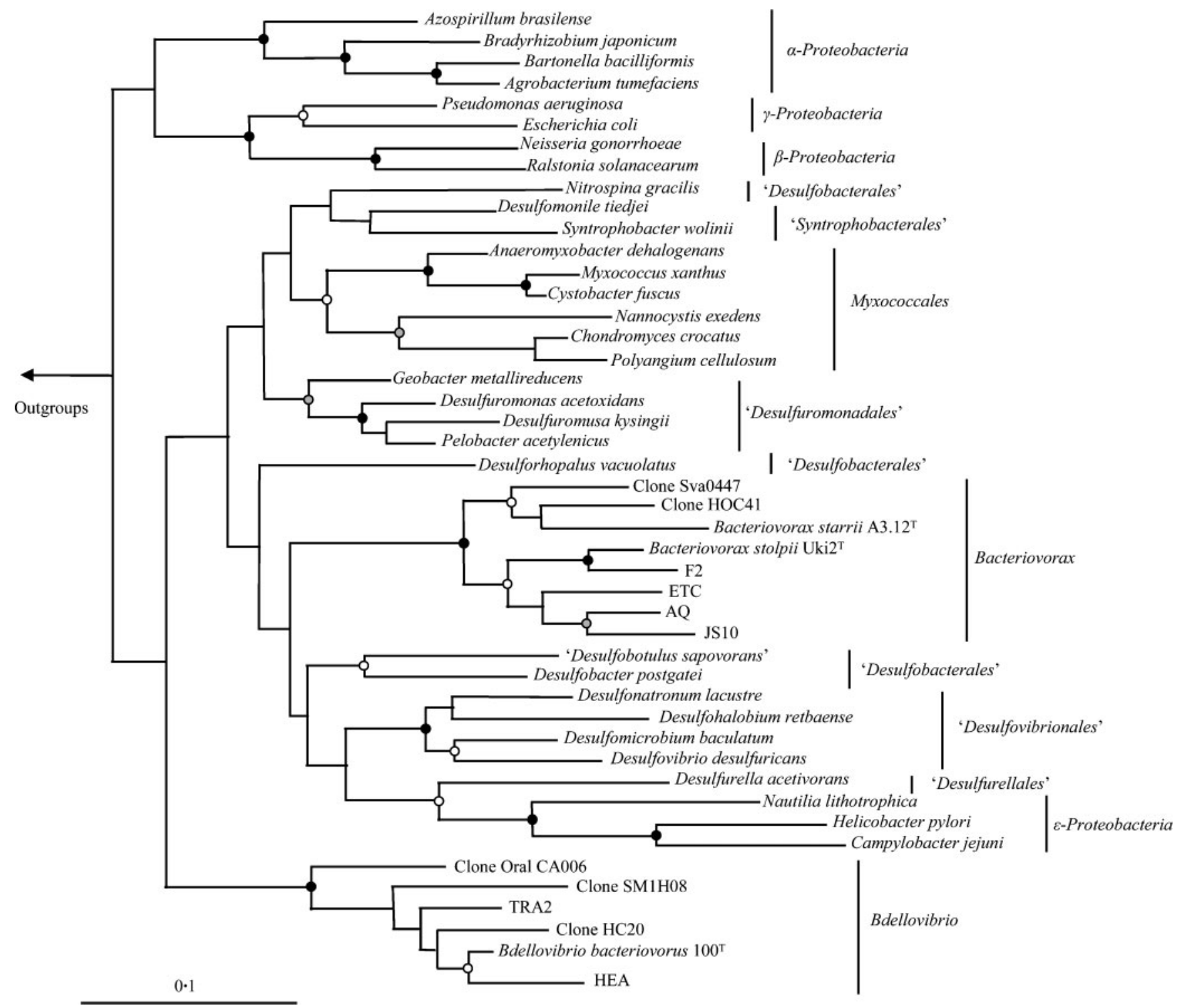

Fig. 4. Phylogenetic tree, based on $16 \mathrm{~S}$ rRNA gene sequences, reflecting the relationships between the BALO lineages and the Proteobacteria. Represented in the tree are all families of the $\delta$ - and $\varepsilon$-Proteobacteria and representatives of the $\alpha$-, $\beta$ - and $\gamma$-Proteobacteria. The tree is based on maximum-likelihood (FastDNAml) analysis, using a $50 \%$ conservation filter. Bootstrap values are indicated as described in Fig. 2. The following collection of non-Proteobacteria was used as the outgroup for treeing: Spirochaeta litoralis, Bacillus subtilis, Deinococcus radiodurans, Microcystis aeruginosa, Mycobacterium leprae, Fibrobacter succinogenes, Cytophaga hutchinsonii, Chlamydia psittaci, Aquifex pyrophilus and Thermotoga maritima. Bar, $10 \%$ estimated sequence divergence.

prokaryotes. BALOs can be viewed as representing a greatly simplified example of intracellular parasitism (Martin, 2002; Moulder, 1985) and can therefore serve as a model for other intracellular prokaryotes exhibiting predatory, symbiotic or pathogenic behaviours. Given the proposed early $\delta$-Proteobacteria branch location for Bdellovibrio, it can be hypothesized that the predatory behaviour of myxobacteria (the order Myxococcales is located within the $\delta$-Proteobacteria) may have also originated from such a common early $\delta$-proteobacterial predatory ancestor.

\section{S rRNA secondary-structure analysis}

Analysis of the 16S rRNA molecule confirmed that specific regions formed secondary structures that were clearly distinguishable between the Bdellovibrio and the Bacteriovorax clades (Schwudke et al., 2001). Helices formed at nucleotide positions 198-219 and 446-488 (Escherichia coli numbering) were considerably shorter in all the Bdellovibrio sequences than in all the Bacteriovorax sequences (see Fig. Aa in IJSEM Online). Long helices at both sites were typical of most other members of the $\delta$-Proteobacteria, but 
some intermediate forms, i.e. short helices at one site, were also found (data not shown). Almost all of the $\beta$ - and $\gamma$-Proteobacteria bore the longer structures, while shorter helices were found in almost all of the members of the $\alpha$ and $\varepsilon$-Proteobacteria. Helix 198-219 was proposed by Woese (1987) as a tool for distinguishing between proteobacterial classes: the $\alpha$-Proteobacteria version was shorter than any of the two $\beta / \gamma$ - or $\delta$-Proteobacteria versions. As a short helix was the common structure found outside Proteobacteria, it may represent the ancestral state. Up-to-date information available in the databases (Cannone et al., 2002; Wuyts et al., 2002) supported these assumptions and suggested a similar development in helix 446-488. These structures appeared to interact and to form a tertiary structure (Gutell et al., 2002), so therefore their co-evolution is plausible. These data lent support to the hypothesis that Bdellovibrio was an early $\delta$-Proteobacteria lineage possessing ancient $16 \mathrm{~S}$ rRNA secondary structures atypical of latter $\delta$-Proteobacteria, while the more recent evolution of the Bacteriovorax clade was reflected by the presence of structures common to the other members of the $\delta$-Proteobacteria.

Comparative analysis of other secondary structures enabled better determination of the internal relationships within the Bdellovibrio and Bacteriovorax lineages: a signature that was found in helix 184-193 (Schwudke et al., 2001) was considerably shorter in all the members of the Bacteriovorax starrii group (the $\mathrm{A} 3.12^{\mathrm{T}}$ group) than in all the other members of the Bacteriovorax lineage. In addition, the structure found in strain ETC (Bacteriovorax cluster VI) at positions 198-219 was shorter than the one found in most of the other Bacteriovorax members (see Fig. Ab in IJSEM Online), suggesting an early branching event in the Bacteriovorax clade. Also, helix 198-219 was longer in strain TRA2 (Bdellovibrio cluster 9) and in clone Oral CA006 (see Fig. Ab in IJSEM Online), which form the most outlying branches in the Bdellovibrio clade.

On the basis of (1) the large internal sequence heterogeneities within the Bdellovibrio ( $>14 \%$ ) and BacteriovoraxPeredibacter $(>16 \%)$ lineages, (2) the great distance separating these clades $(>20 \%)$, (3) the fact that they do not form a monophyletic group, (4) the very low DNA-DNA hybridization values seen between sampled members of these groups (Baer et al., 2000), and (5) the differences observed in 16S rRNA secondary structures at positions 198-219, typical of other $\delta$-Proteobacteria (see the supplementary data in IJSEM Online; Schwudke et al., 2001), we propose the reclassification of the Bdellovibrio and BacteriovoraxPeredibacter groups into two families, i.e. the existing 'Bdellovibrionaceae' and Bacteriovoracaceae fam. nov., respectively. The large phylogenetic diversity within these groups suggests that each is composed of additional undefined species and genera for which more data are needed to complete their taxonomic definition. No clear data concerning characteristics unique to these two families are available, but since they are so phylogenetically distant, new information will surely emerge when genomic projects are completed.

\section{Re-evaluation of BALO-targeted oligomers}

Only a few $16 \mathrm{~S}$ rRNA-targeted, BALO-specific oligonucleotides are available (Jurkevitch \& Ramati, 2000). Oligomer 842 was designed as a BALO-specific oligonucleotide, under the assumption that BALOs form one clade. This wrong assumption was probably the reason why this oligomer was not $100 \%$ specific for BALOs and included non-BALO bacteria (Jurkevitch \& Ramati, 2000). A re-evaluation of its sensitivity showed that the sequences from 13 out of the 17 clusters described in this study fully matched, or exhibited only one mismatch with, oligomer 842. In combination with a Bacteria-domain-targeted primer, amplification from strains belonging to these 13 clusters was positive under all stringencies used. Amplicons could be obtained with sequences exhibiting two mismatches (clusters 2 and VIII) under low stringency (annealing temperature $<52{ }^{\circ} \mathrm{C}$ ) but were usually impossible to obtain with sequences exhibiting three or more mismatches (clusters II and VI). Oligomers 434R and 483R, which were designed as Bdellovibrio- and Bacteriovorax stolpii-specific oligonucleotides, respectively (Jurkevitch \& Ramati, 2000), excluded all non-BALO sequences. Whilst oligomer 434R exhibited up to two mismatches with Bdellovibrio sequences (in clusters 2 and 8), oligomer 483 showed one mismatch, at most, with Uki2 ${ }^{\mathrm{T}}$ group members (clusters I and II). However, it exhibited five or more mismatches with all the other members of the Bacteriovorax clade. In conclusion, the re-evaluation of published BALO-targeted oligonucleotides showed that they are useful tools for the analysis of isolated strains but that they are not sensitive or specific enough for precise culture-independent analysis of BALO populations in environmental samples. The extensive phylogenetic data obtained provide a robust basis for the design of new oligomers which will enable the implementation of cultivation-independent BALO studies.

\section{Description of Bacteriovoracaceae fam. nov.}

Bacteriovoracaceae (Bac.te.ri.o.vo'ra.ca'ce.ae. N.L. fem. n. Bacteriovorax the genus of Gram-negative, aerobic, predators of Gram-negative bacteria, the type genus of the family; suffix acaeae denoting a family; N.L. fem. pl. n. Bacteriovoracaceae the Bacteriovorax family - the feminine gender was chosen).

The description of Bacteriovoracaceae is based on the description of the genus Bacteriovorax by Baer et al. (2000) and our own data. Gram-negative, comma-shaped rods, $0 \cdot 5-1 \cdot 4 \mu \mathrm{m}$ in length. Wild-type cells, which are obligate predators of Gram-negative bacteria, exhibit a biphasic life cycle, including a periplasmic stage within the prey. Cells in their free-swimming stage are motile by means of a single, polar flagellum. Predator-independent mutants can grow saprophytically in rich nutrient medium. They are pleomorphic, exhibiting a range of cell shapes, from simple rods to long, tightly spirally shaped cells. Oxidase- and catalasepositive. Some predator-independent mutants may demonstrate variable catalase activity as some strains have been 
shown to lose this ability upon repeated transfer. Obligately aerobic. The $\mathrm{G}+\mathrm{C}$ content ranges from $41 \cdot 0$ to $43 \cdot 5 \mathrm{~mol} \%$. Members of the family exhibit no DNA-DNA hybridization $(<4 \%)$ with the 'Bdellovibrionaceae', although they were previously considered to belong to that family. Members of the family are found in terrestrial and aquatic environments, including marine habitats, while the 'Bdellovibrionaceae' are not found in halophilic environments. Some members of the family grow optimally below $20^{\circ} \mathrm{C}$, while the optimal temperature of others is around $30^{\circ} \mathrm{C}$. $16 \mathrm{~S}$ rRNA gene sequence analysis shows that the members of the genera Bacteriovorax and Peredibacter are more related one to another (maximum divergence $<17 \%$ ) than to the 'Bdellovibrionaceae' clade (minimum divergence $>20 \%$ ). Together, the 'Bdellovibrionaceae' and the Bacteriovoracaceae do not form a monophyletic group. Secondary structures of the 16S rRNA (Escherichia coli positions 198-219 and 446-488) are typical of the $\delta$-Proteobacteria and differ from those found in the 'Bdellovibrionaceae'. Total genomic restriction digest patterns (PFGE) for Bacteriovorax stolpii $\mathrm{Uki2}^{\mathrm{T}}$ and Peredibacter starrii $\mathrm{A} 3.12^{\mathrm{T}}$ exhibit little similarity to the patterns produced by members of the 'Bdellovibrionaceae'.

The type genus is Bacteriovorax Baer et al. 2000.

\section{Description of Peredibacter gen. nov.}

Peredibacter (Pe.re.di.bac'ter. L. v. peredere to eat up, to devour; N.L. masc. n. bacter rod; N.L. masc. n. Peredibacter bacterium-devourer).

Consists of predatory, Gram-negative, bacteriovorous species that require a Gram-negative host as prey to complete a biphasic life cycle. Members of the genus are soil-dwellers. Phylogenetic rRNA gene sequence analysis shows that it forms a separate, monophyletic group within the Bacteriovoracaceae.

The morphological description of the genus is the same as that of the type strain and only species in the genus, Peredibacter starrii.

\section{Description of Peredibacter starrii comb. nov.}

Peredibacter starrii (star'ri.i. N.L. gen. masc. n. starrii of Starr, named after the American microbiologist Mortimer P. Starr).

Basonym: Bacteriovorax starrii (Seidler et al. 1972) Baer et al. 2000.

The description of the species is based on that by Baer et al. (2000), following Seidler et al. (1972). All members of the species were isolated from soil. Its major cellular fatty acids are $16: 1 \omega 9 c, 13: 0$ iso, $13: 0$ and $15: 1 \omega 8 c$. Sensitivity to the antibiotics penicillin, streptomycin, neomycin, kanamycin, gentamicin, methicillin and vancomycin has been shown in $\mathrm{A} 3.12^{\mathrm{T}}$, but, in contrast to Bacteriovorax stolpii $\mathrm{Uki}^{\mathrm{T}}$, $\mathrm{A} 3.12^{\mathrm{T}}$ is resistant to pteridine $0 / 129$ and nalidixic acid. The optimal temperature range is $20-30{ }^{\circ} \mathrm{C}$. Phylogenetically its closest species is Bacteriovorax stolpii, as shown by $16 \mathrm{~S}$ rRNA gene sequence analysis (divergence $>12 \cdot 5 \%$ ).

The type strain is $\mathrm{A} 3.12^{\mathrm{T}}$ (=ATCC $15145^{\mathrm{T}}=\mathrm{NCCB}$ $\left.72004^{\mathrm{T}}\right)$. Isolated from soil in California, using Pseudomonas fluorescens ATCC 12633 as prey. Its G $+\mathrm{C}$ ratio is $43 \cdot 5 \mathrm{~mol} \%$ (Seidler et al., 1972).

\section{ACKNOWLEDGEMENTS}

This research was supported by The Israel Science Foundation founded by The Academy of Sciences and Humanities (grants 132/99 and 486/03). We thank J. Euzéby for assistance with the nomenclature, and Y. Okon for useful suggestions.

\section{REFERENCES}

Baer, M. L., Ravel, J., Chun, J., Hill, R. T. \& Williams, W. N. (2000). A proposal for the reclassification of Bdellovibrio stolpii and Bdellovibrio starrii into a new genus, Bacteriovorax gen. nov., as Bacteriovorax stolpii comb. nov. and Bacteriovorax starrii comb. nov., respectively. Int J Syst Evol Microbiol 50, 219-224.

Cannone, J. J., Subramanian, S., Schnare, M. N. \& 11 other authors (2002). The comparative RNA web (CRW) site: an online database of comparative sequence and structure information for ribosomal, intron, and other RNAs. BMC Bioinformatics 3, 2.

Castro, H. F., Williams, N. H. \& Ogram, A. (2000). Phylogeny of sulfate-reducing bacteria. FEMS Microbiol Ecol 31, 1-9.

Cohan, F. M. (2002). What are bacterial species? Annu Rev Microbiol 56, 457-487.

Donze, D., Mayo, J. A. \& Diedrich, D. L. (1991). Relationship among bdellovibrios revealed by partial sequences of $16 \mathrm{~S}$ ribosomal RNA. Curr Microbiol 23, 115-119.

Felsenstein, J. (1992). Phylogenies from restriction sites - a maximum-likelihood approach. Evolution 46, 159-173.

Fox, G. E., Wisotzkey, J. D. \& Jurtshuk, P., Jr (1992). How close is close: $16 \mathrm{~S}$ rRNA sequence identity may not be sufficient to guarantee species identity. Int J Syst Bacteriol 42, 166-170.

Fuhrman, J. A. (1999). Marine viruses and their biogeochemical and ecological effects. Nature 399, 541-547.

Garrity, G. M., Johnson, K. L., Bell, J. A. \& Searles, D. B. (2002). Taxonomic outline of the procaryotes. In Bergey's Manual of Systematic Bacteriology, 2nd edn. Release 3.0. New York: Springer.

Giovannoni, S. J., Britschgi, T. B., Moyer, C. L. \& Field, K. G. (1990). Genetic diversity in Sargasso Sea bacterioplankton. Nature 345, 60-63.

Glöckner, F. O., Zaichikov, E., Belkova, N., Denissova, L., Pernthaler, J., Pernthaler, A. \& Amann, R. (2000). Comparative $16 S$ rRNA analysis of lake bacterioplankton reveals globally distributed phylogenetic clusters including an abundant group of actinobacteria. Appl Environ Microbiol 66, 5053-5065.

Gutell, R. R., Lee, J. C. \& Cannone, J. J. (2002). The accuracy of ribosomal RNA comparative structure models. Curr Opin Struct Biol 12, 301-310.

Heyndrickx, M., Vauterin, L., Vandamme, P., Kersters, K. \& De Vos, P. (1996). Applicability of combined amplified ribosomal DNA restriction analysis (ARDRA) patterns in bacterial phylogeny and taxonomy. J Microbiol Methods 26, 247-259. 
Hoeniger, J. F., Ladwig, R. \& Moor, H. (1972). The fine structure of "resting bodies" of Bdellovibrio sp. strain W developed in Rhodospirillum rubrum. Can J Microbiol 18, 87-92.

Jürgens, K., Pernthaler, J., Schalla, S. \& Amann, R. (1999). Morphological and compositional changes in a planktonic bacterial community in response to enhanced protozoan grazing. Appl Environ Microbiol 65, 1241-1250.

Jurkevitch, E. (2000). The genus Bdellovibrio. In The Prokaryotes. Edited by M. Dworkin, E. Rosenberg, K. H. Schleifer \& E. Stackebrandt. New York: Springer (http://141.150.157.117:8080/ prokPUB/index.htm).

Jurkevitch, E. \& Ramati, B. (2000). Design and uses of a Bdellovibrio 16S rRNA-targeted oligonucleotide. FEMS Microbiol Lett 184, 265-271.

Jurkevitch, E., Minz, D., Ramati, B. \& Barel, G. (2000). Prey range characterization, ribotyping, and diversity of soil and rhizosphere Bdellovibrio spp. isolated on phytopathogenic bacteria. Appl Environ Microbiol 66, 2365-2371.

Ludwig, W., Strunk, O., Klugbauer, S., Klugbauer, N., Weizenegger, M., Neumaier, J., Bachleitner, M. \& Schleifer, K. H. (1998). Bacterial phylogeny based on comparative sequence analysis. Electrophoresis 19, 554-568.

Marchesi, J. R., Sato, T., Weightman, A. J., Martin, T. A., Fry, J. C., Hiom, S. J., Dymock, D. \& Wade, W. G. (1998). Design and evaluation of useful bacterium-specific PCR primers that amplify genes coding for bacterial 16S rRNA. Appl Environ Microbiol 64, 795-799.

Martin, M. O. (2002). Predatory prokaryotes: an emerging research opportunity. J Mol Microbiol Biotechnol 4, 467-477.

Mathews, D. H., Sabina, J., Zuker, M. \& Turner, D. H. (1999). Expanded sequence dependence of thermodynamic parameters improves prediction of RNA secondary structure. J Mol Biol 288, 911-940.

Moulder, J. W. (1985). Comparative biology of intracellular parasitism. Microbiol Rev 49, 298-337.

Philippe, H. \& Laurent, J. (1998). How good are deep phylogenetic trees? Curr Opin Genet Dev 8, 616-623.

Ronn, R., McCaig, A. E., Griffiths, B. S. \& Prosser, J. I. (2002). Impact of protozoan grazing on bacterial community structure in soil microcosms. Appl Environ Microbiol 68, 6094-6105.

Rossello-Mora, R. \& Amann, R. (2001). The species concept for prokaryotes. FEMS Microbiol Rev 25, 39-67.

Sanchez-Amat, A. \& Torrella, F. (1990). Formation of stable bdelloplasts as a starvation survival strategy of marine bdellovibrios. Appl Environ Microbiol 56, 2717-2725.

Schwudke, D., Strauch, E., Krueger, M. \& Appel, B. (2001). Taxonomic studies of predatory bdellovibrios based on 16S rRNA analysis, ribotyping and the hit locus and characterization of isolates from the gut of animals. Syst Appl Microbiol 24, 385-394.
Seidler, R. J., Mandel, M. \& Baptist, J. N. (1972). Molecular heterogeneity of the bdellovibrios: evidence of two new species. J Bacteriol 109, 209-217.

Snyder, A. R., Williams, H. N., Baer, M. L., Walker, K. E. \& Stine, O. C. (2002). 16S rDNA sequence analysis of environmental Bdellovibrioand-like organisms (BALO) reveals extensive diversity. Int J Syst Evol Microbiol 52, 2089-2094.

Stackebrandt, E. \& Goebel, B. M. (1994). Taxonomic note: a place for DNA-DNA reassociation and $16 \mathrm{~S}$ rRNA sequence analysis in the present species definition in bacteriology. Int J Syst Bacteriol 44, 846-849.

Stolp, H. \& Starr, M. P. (1963). Bdellovibrio bacteriovorus gen. et sp. n., a predatory, ectoparasitic, and bacteriolytic microorganism. Antonie Van Leeuwenhoek 29, 217-248.

Strunk, O., Gross, O., Reichel, B. \& 11 other authors (1999). ARB: a software environment for sequence data (http://www.mikro. biologie.tu-muenchen.de). Munich: Department of Microbiology, Technische Universität München.

Teske, A., Wawer, C., Muyzer, G. \& Ramsing, N. B. (1996). Distribution of sulfate-reducing bacteria in a stratified fjord (Mariager Fjord, Denmark) as evaluated by most-probablenumber counts and denaturing gradient gel electrophoresis of PCR-amplified ribosomal DNA fragments. Appl Environ Microbiol 62, 1405-1415.

Torsvik, V., Ovreas, L. \& Thingstad, T. F. (2002). Prokaryotic diversity - magnitude, dynamics, and controlling factors. Science 296, 1064-1066.

Vandamme, P., Pot, B., Gillis, M., De Vos, P., Kersters, K. \& Swings, J. (1996). Polyphasic taxonomy, a consensus approach to bacterial systematics. Microbiol Rev 60, 407-438.

Varon, M. \& Shilo, M. (1980). Ecology of aquatic bdellovibrios, pp. 1-48. In Advances in Aquatic Microbiology, vol. 2. Edited by M. R. Droop \& H. W. Jannasch. New York: Academic Press.

Wayne, L. G., Brenner, D. J., Colwell, R. R. \& 9 other authors (1987), International Committee on Systematic Bacteriology. Report of the ad hoc committee on reconciliation of approaches to bacterial systematics. Int J Syst Bacteriol 37, 463-464.

Williams, H. N., Scheoffield, A. J., Guether, D., Kelley, J., Shah, D. \& Falker, W. A. (1995). Recovery of bdellovibrios from submerged surfaces and other aquatic habitats. Microb Ecol 29, 39-48.

Woese, C. R. (1987). Bacterial evolution. Microbiol Rev 51, 221-271.

Wright, T. D., Vergin, K. L., Boyd, P. W. \& Giovannoni, S. J. (1997). A novel $\delta$-subdivision proteobacterial lineage from the lower ocean surface layer. Appl Environ Microbiol 63, 1441-1448.

Wuyts, J., Van de Peer, Y., Winkelmans, T. \& De Wachter, R. (2002). The European database on small subunit ribosomal RNA. Nucleic Acids Res 30, 183-185. 